\title{
Geothermal phenomena in the context of gravity-driven basinal flow of groundwater
}

\author{
József Tóth* \\ Department of Earth and Atmospheric Sciences, University of Alberta, Edmonton, Canada
}

Received: January 28, 2015; accepted: January 28, 2015

Gravity-driven groundwater flow systems function in topographic basins as subsurface conveyor belts. They pick up and move fluids, gases, solutes, colloids, particulate matter and heat from loading sites in recharge areas and/or on their way to the discharge areas and can deliver them "en route" or in discharge regions. Gravitational flow systems of various horizontal and vertical extents are organized into hierarchically nested complex patterns controlled by the configuration of the water table's relief and modified by the rock framework's heterogeneities of permeability. The systems are ubiquitous and act simultaneously on broad ranges of the spatial and temporal scales of measurement. Their universal geologic agency is manifest by numerous different, even disparate, natural processes and phenomena. Several of these are associated with geothermal heat flow. The understanding of geothermal phenomena in the context of basinal flow systems requires, therefore, an intimate familiarity with the overarching "Theory of regional groundwater flow" which, in turn, comprises two component theories: "The hydraulics of basin-scale groundwater flow systems" and "The geologic agency of basin-scale groundwaterflow-systems". The paper's outline is based on this conceptual structure. The paper presents examples for geothermal effects of groundwater flow by means of the first theoretical models and some case studies of thermal springs and wells, and petroleum accumulations. The final section reflects the author's conviction that geothermal studies cannot be complete without consideration and understanding of the area's groundwater flow regime.

Keywords: groundwater, flow system, basin-scale, geologic agent, geothermal phenomena, anomaly

\footnotetext{
* Corresponding address: 1-26 Earth Sciences Bldg, AB, T6G 2E3 Edmonton, Canada;

E-mail: joe.toth@ualberta.ca
} 


\section{Introduction}

The intent of the paper is, first, to demonstrate that gravity-driven basinal groundwater flow is capable of generating diagnostic anomalies of geothermal heat which are systematically distributed in space. Second, to argue, that geothermal studies of an extended area are incomplete without an analysis of basin-scale groundwater flow. An appreciation of these propositions requires the simultaneous understanding of three parts of the question, namely: i) the hydraulics of basin-scale groundwater flow; ii) the geologic agency of regional groundwater flow; and iii) the transport of geothermal heat by moving groundwater. Parts i) and ii) are two component theories which together constitute the bimodal theory of regional groundwater flow. Essential aspects of part iii) are illustrated in the section on geothermal phenomena.

Figure 1 is a pictorial summary of some properties and manifestations of basin-scale groundwater flow relevant to the question of geothermal phenomena. The figure shows an idealized basin with one single flow system on the left-side flank of insignificant local relief, and a hierarchical set of local, intermediate and regional

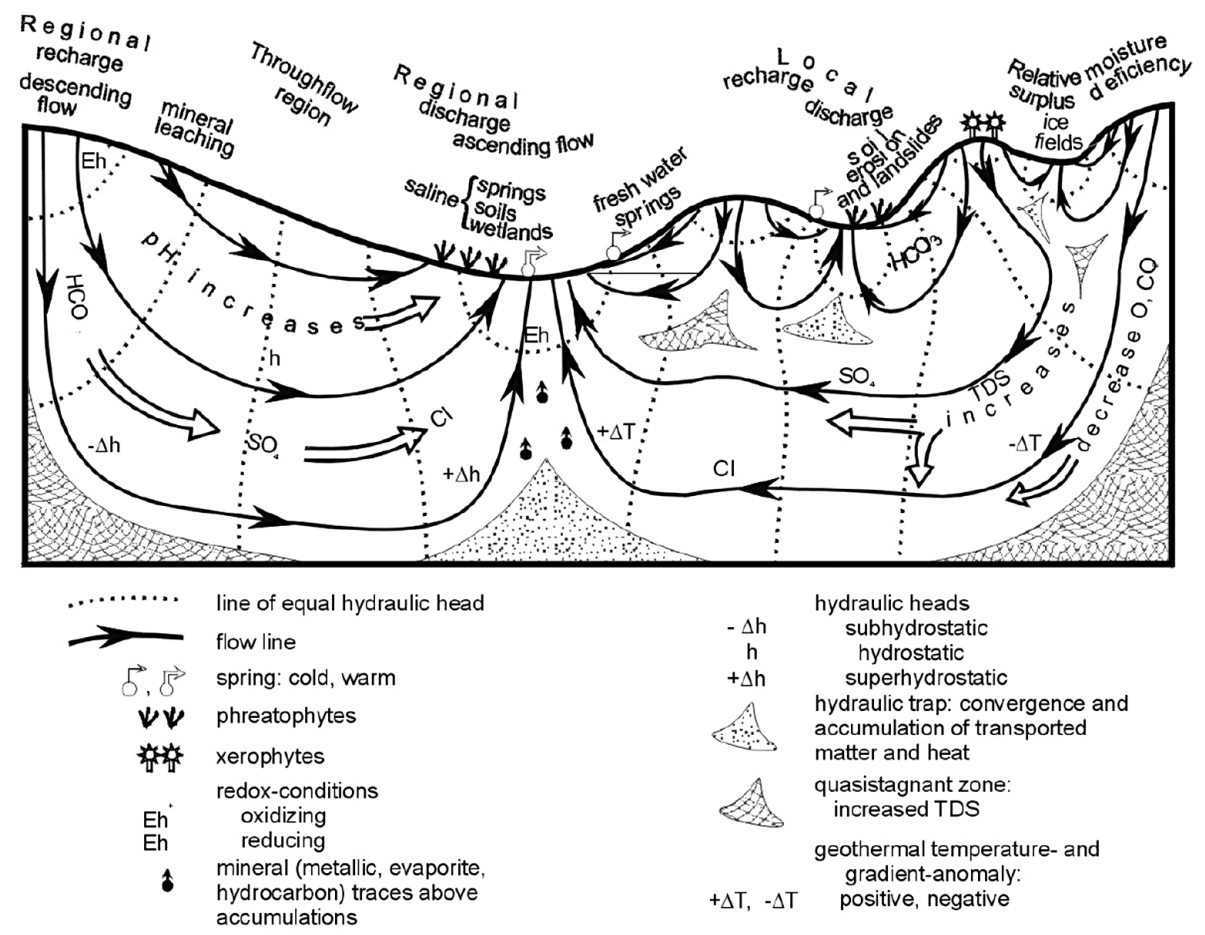

Fig. 1

Schematic summary of the effects and manifestations of groundwater flow in a regionally unconfined drainage basin (Tóth 1980, 1999, 2009) 
flow systems on the right flank of undulating topography. Each flow system, regardless of its hierarchical rank, has an area of origin or recharge, an area of through-flow or transfer, and one of termination or discharge (see section on Basic concepts). In the recharge areas, the hydraulic heads are high relative to their immediate surroundings and decrease with increasing depth; water flow is downward and divergent. The energy and flow conditions are reversed in the discharge areas: hydraulic heads are low relative to their surroundings and increase downward, resulting in converging and ascending water flow. In the areas of through-flow, the water's mechanical energy is largely invariant with depth (the isopotential lines are sub-vertical) and flow is chiefly lateral. The flow systems operate as conveyor belts which effectively interact with their ambient environment. The interaction results in in situ environmental effects while the flow serves as the mechanism for mobilization, transport and distribution, and accumulation of the products.

Typical environmental effects and conditions due to gravity-flow systems of groundwater are illustrated in Fig. 1 which include: 1) subhydrostatic, hydrostatic, and superhydrostatic hydraulic heads at depth along the flow lines from recharge, to discharge areas, respectively; 2) relatively dry surface-water and soil-moisture conditions (negative water balance) in recharge areas, and water surplus (positive water balance), possibly resulting in wetlands, in discharge areas (these conditions are expressed in comparison to an average water-table depth resulting solely from precipitation and evapotranspiration on a horizontal tract of land); 3) systematic changes in the water's anion facies, from $\mathrm{HCO}_{3}$ through $\mathrm{SO}_{4}$ to $\mathrm{Cl}$, both along flow systems and with depth; 4) soils and near-surface rocks leached chemically in areas of inflow, but increased salt contents possibly amounting to salt-affected soils or even commercial salt deposits at flow-system terminuses; 5) saline marshes in situations where wetland conditions and intensive salt supply coincide; 6) negative and positive anomalies of geothermal heat and geothermal gradients beneath areas of descending and ascending flows, respectively; 7) chemically oxidizing and reducing conditions in the near-surface environment of recharge and discharge areas, respectively; 8) identifiable response in the type and quality of the vegetation cover to the contrasting nutrient and moisture conditions generated by the inflow and outflow of groundwater at flow-system extremities; 9) increased vulnerability of the land surface to soil- and rock-mechanical failures (such as soil erosion, slumping, quick grounds, and landslides) in areas of discharge, possibly developing into major geomorphologic features, e.g. gullying and stream meanders; 10) accumulation of transported mineral matter such as metallic ions (iron, uranium, sulfides of various metals), hydrocarbons, and anthropogenic contaminants, primarily in regions where flow paths converge from opposite directions (hydraulic traps) or in regions where the fluid potential is minimum with respect to that of a transported immiscible fluid (oil, gas), e.g. at grain-size boundaries or in rocks of adsorptive minerals. Specific aspects of all mentioned processes and phenomena are subject to local and regional influences of climate, season, geology, morphology, and other environmental conditions. 


\section{Basic concepts of the hydraulics of gravity-driven basin-scale flow of groundwater}

\section{Effect of the relief of the water-table}

The "Unit Basin": The basic pattern of regional groundwater flow. The Unit Ba$\sin$ is the elementary building concept in the theory of gravity-driven regional (or basinal) groundwater flow. It is envisaged as a two-dimensional vertical slab of unit thickness and of homogeneous and isotropic hydraulic conductivity of the Earth's crust (Fig. 2). On the top, it is bounded by an axially symmetrical topographic depression with water tables rising linearly from the central thalweg to the divides, by an effectively impermeable horizontal stratum at the base, and by two vertical planes forming the sides beneath the water divides. The sides are considered impervious to flow owing to the water table's mirror symmetry relative to the divides. The basic pattern of regional groundwater flow is a steady-state flow-field which develops in a saturated Unit Basin with gravity being the sole water-driving force. General flow patterns may be thought of as modified versions of the basic pattern. Commonly, general patterns can be resolved into cells or compartments in which flow characteristics are similar to those of the basic pattern.

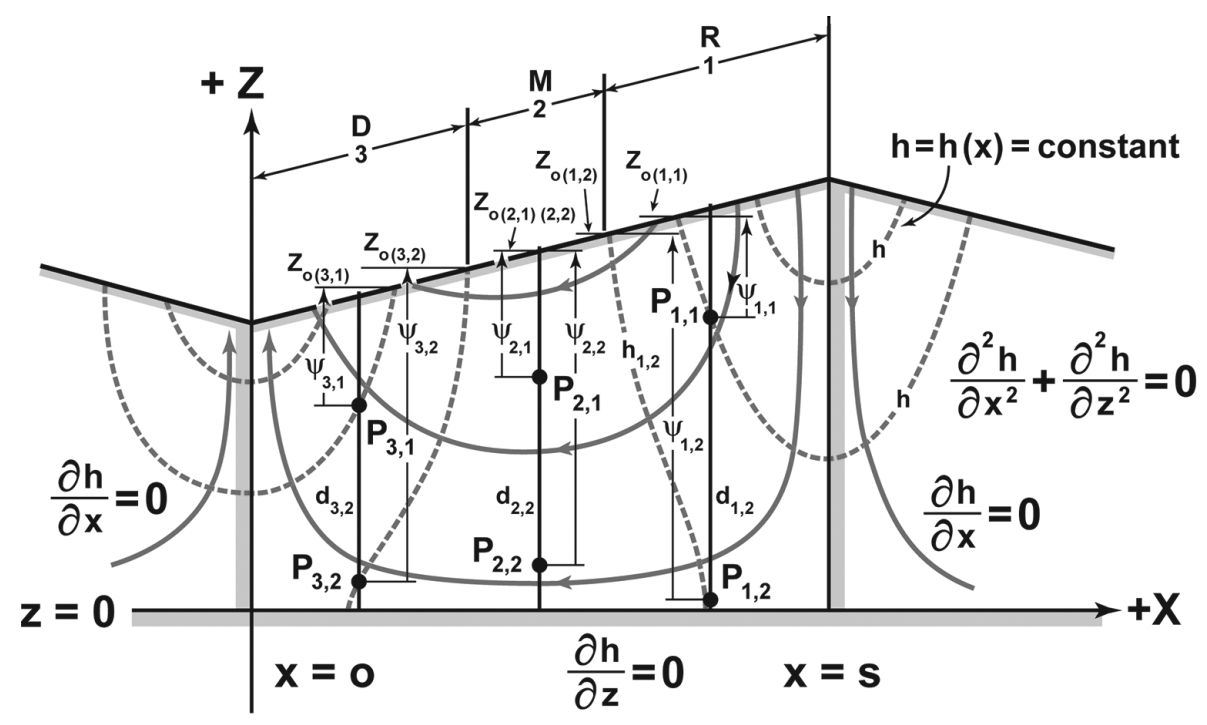

R, M, D : Area of Recharge, Midline, Discharge, respectively;

$\mathbf{P}_{1,2}$ : point of measurement in cased well; $d_{1,2}$ : well depth; $\psi_{1,2}$ : pressure head;

$\mathbf{h}$ : hydraulic head; $\mathbf{z}_{\mathrm{o}(1,2)}$ : intersection of isopotential $\mathbf{h}_{1,2}$ with water table

Fig. 2

Patterns of hydraulic head, h(x,z), and groundwater flow, q(x,z), in the Unit Basin (Tóth 2009) 
The Unit Basin as defined above is a conservative flow domain. In a conservative domain no sources or sinks of energy or flow occur. The distributions of hydraulic head and flow can thus be calculated by the Laplace Equation (Equation 1) using the appropriate boundary conditions (Fig. 1; Tóth 1962; Freeze and Witherspoon 1967; Wang and Anderson 1982; Zijl and Nawalany 1993).

$\frac{\partial^{2} h}{\partial x^{2}}+\frac{\partial^{2} h}{\partial y^{2}}+\frac{\partial^{2} h}{\partial z^{2}}=\nabla^{2} h=0$

Owing to the geometrical symmetry of the water table with respect to the Z-axis, the $(\mathrm{y}, \mathrm{z})$ planes may be considered as impermeable boundaries at $\mathrm{x}=\mathrm{o}$ and $\mathrm{x}=\mathrm{s}$. Consequently, a flow pattern obtained for one flank of the basin is the mirror image of the flow distribution in the opposite flank. The boundary conditions for the two sides and the base of the basin are, therefore:

$$
\left(\frac{\partial h}{\partial x}\right)_{x=0}=\left(\frac{\partial h}{\partial x}\right)_{x=s}=\left(\frac{\partial h}{\partial z}\right)_{z=0}=0
$$

The upper boundary of the flow field is the water table. Along the water table the hydraulic head $h_{w t}$ is a linear function of the distance $\mathrm{x}$ from the center of the basin:

$h_{w t}=h_{w t}(x)$

The Laplace Equation, combined with the four boundary conditions, yields the solution for the hydraulic head distribution in the Unit Basin as follows (Tóth 1962):

$h=\left(z_{0}+\frac{c s}{2}\right)-\frac{4 g c s}{\pi^{2}} \sum_{m=0}^{\infty} \frac{\cos \left[(2 m+1) \frac{\pi x}{s}\right] \cosh \left[(2 m+1) \frac{\pi z}{s}\right]}{(2 m+1)^{2} \cosh \left[(2 m+1) \frac{\pi z_{0}}{s}\right]}$

where $\mathrm{m}=1,2,3 \ldots . . \infty$. With Equation 3 the hydraulic head values, h, can be calculated for any point, $\mathrm{P}_{\mathrm{X}, \mathrm{Z}}$, in the Unit Basin characterized by depth, $\mathrm{z}_{\mathrm{O}}$, at the thalweg, regional slope of the water table $\mathrm{c}=\tan \alpha$ (the angle between horizontal and the water table in Fig. 2), and width, s, of one flank. Equipotential lines can be obtained by connecting points of equal hydraulic heads. A complete flow net can be produced by drawing flow lines normal to the equipotential lines.

Figure 2 illustrates one flank of a Unit Basin with the basic patterns of groundwater flow and hydraulic head. Three functionally different flow-regimes can be distinguished: the hydraulic regimes of recharge or inflow, $\boldsymbol{R}$; transfer or throughflow, $\boldsymbol{M}$; and discharge or outflow, $\boldsymbol{D}$. These regimes are located in the areas, respectively, upslope, adjacent, and downslope, relative to the hydraulic midline. Relative to the water table, the direction of flow is descending, lateral, and ascending, respectively, in the 
three hydraulic regimes. The flow intensity, q, decreases with increasing depth and away from the midline area. In the lower corners of the flow field near stagnant, or "quasi-stagnant", conditions prevail. If the midline is interpreted in the strict sense, i.e. that it has no areal extent, the ratio of the area of recharge to the area of discharge is $\mathrm{R} / \mathrm{D}=1$. In case of a non-ideally linear water table, e.g. concave or convex, the ratio may be less or greater than 1 , respectively.

The physical meaning and numerical value of the hydraulic-head distribution may be visualized by interpreting the potentiometric contours, $\mathrm{h}=$ const., in terms of elevations to which water would rise in vertical bore-holes from points, $P_{X, Z}$. These water levels can be determined by noting that the value of the hydraulic head in any point along a given contour line, $h_{i}$, is equal to the elevation of the water table at its intersection with the specified contour: $\mathrm{h}_{\mathrm{i}}=\mathrm{h}_{\mathrm{wt}}=\mathrm{z}_{\mathrm{O}}$. Consequently, water will rise from any point on a hydraulic head contour to the elevation at which that particular contour intersects the water table. Thus, in Fig. 2, water from point $\mathrm{P}_{1,1}$ will rise to elevation $\mathrm{z}_{\mathrm{O}_{(1,1)}}$, while from point $\mathrm{P}_{1,2}$ it rises to $\mathrm{z}_{\mathrm{O}_{(1,2)}}$. Because elevation $\mathrm{z}_{\mathrm{O}_{(1,1)}}$ is higher than $\mathrm{z}_{\mathrm{O}_{(1,2)}}$, a downward sense of the vertical flow component is indicated. By similar considerations it can be determined that water levels in points $\mathrm{P}_{2,1}$ and $\mathrm{P}_{2,2}$ in the midline region are equal, namely, $\mathrm{z}_{\mathbf{O}_{(2,1)}}=\mathrm{z}_{\mathrm{O}_{(2,2)}}$, whereas water rises from the shallow point $\mathrm{P}_{3,1}$ to the low elevation of $\mathrm{z}_{\mathrm{O}_{(3,1)}}$ and from the deep $\mathrm{P}_{3,2}$ to the higher $\mathrm{z}_{\mathbf{O}_{(3,2)} \text {. }}$.

In summary, the hydraulic head pattern of the Unit Basin is characterized by water levels that decline, are constant, and rise with depth in the recharge, hydraulic midline, and discharge areas, respectively. In map view, the hydraulic heads are maximum at the basin's divide and minimum at the valley bottom. The hydraulic gradients decrease generally with increasing depth. Theoretically, they become zero in the two lower corners of the basin. Such regions of sluggish or zero formation-water flow can favor accumulation of natural mineral matter, anthropogenic waste, or geothermal heat, and play a role in the entrapment of petroleum.

Composite topographic basins: Hierarchically nested flow systems

Changes to the geometry of the Unit Basin modify the patterns of flow and fluid-dynamic parameters. One of the most important factors affecting the geometry of the flow field is the relief of the water table (Tóth 1963; Zijl and Nawalany 1993; Robinson and Love 2013).

The basic effects of the water table's configuration on groundwater flow patterns in basins of homogeneous rock framework can be studied by substituting a sinusoidal surface for the linear upper boundary of the Unit Basin (Tóth 1963). Recalling that the hydraulic head at a given point of the water table, $h_{w t}$, is equal to the water table's elevation at that point (Fig. 2), the hydraulic head along the sinusoidal upper boundary is (Fig. 3):

$h_{w t}=z_{0}+x \tan \alpha+a \frac{\sin \left(\frac{b x}{\cos \alpha}\right)}{\cos \alpha}$ 
where $\mathrm{z}_{\mathrm{O}}$ : elevation of valley bottom above base; $\mathrm{x}$ : horizontal distance from the thalweg; $\alpha$ : angle of the regional slope; and $a, \lambda$, and $b=2 \pi / \lambda$ : amplitude, wave length, and wave number, respectively, of the water table undulation.

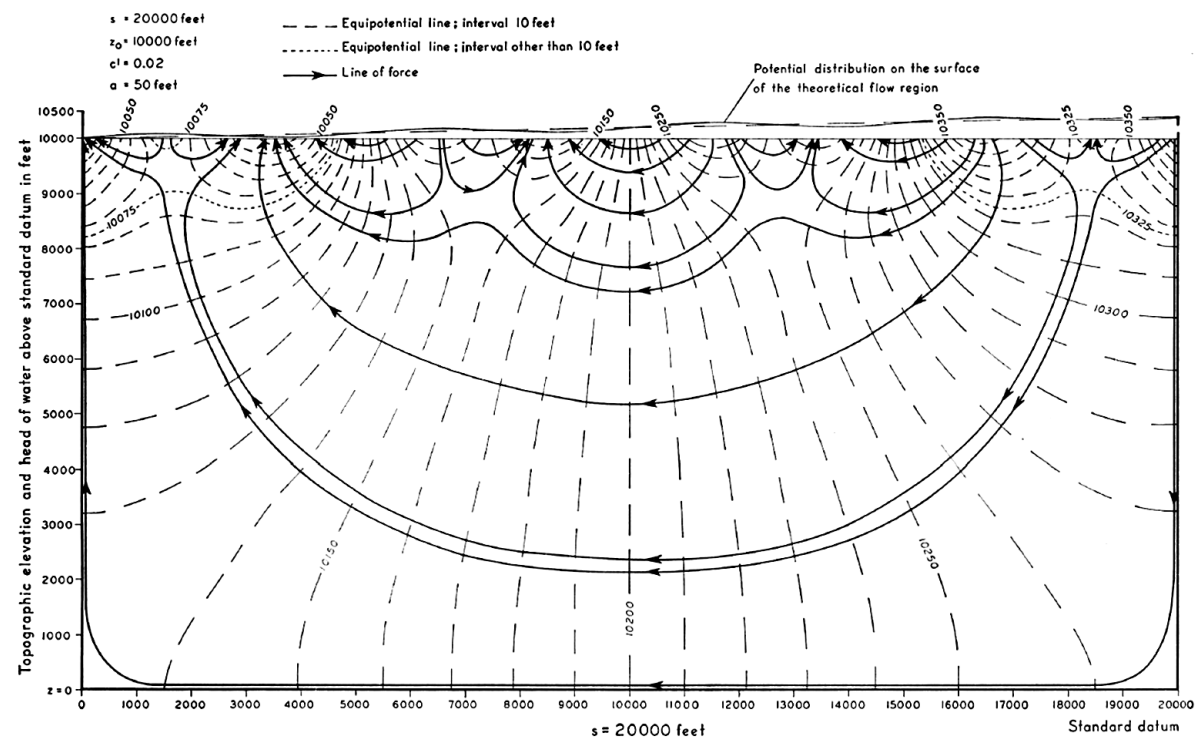

Fig. 3

Idealized cross-section of a drainage basin's valley flank of sinusoidal water table (Tóth 1963)

Using the substitutions $c^{\prime}=\tan \alpha$, a' $=a / \cos \alpha$, and $b^{\prime}=b / \cos \alpha$, with Eq. $4 a$, the hydraulic head on the upper boundary is:

$$
h_{w t}=z_{0}+c^{\prime} x+a^{\prime} \sin b^{\prime} x
$$

The conditions for the three no-flow boundaries are identical to those established for the Unit Basin (Eq. 2a)

The solution of the Laplace Equation (Eq. 1) with the four boundary conditions (Eqs. 2a and 4b) is (Tóth 1963; Tóth 2009):

$$
\begin{aligned}
& h=z_{0}+\frac{c^{\prime} s}{2}+\frac{a^{\prime}}{s b^{\prime}}\left(1-\cos \left(b^{\prime} s\right)\right)+ \\
& +2 \int_{m=1}^{\infty}\left[\frac{a^{\prime} b^{\prime}\left(1-\cos \left(b^{\prime} s\right) \cos (m \pi)\right)}{b^{\prime 2}-\frac{m^{2} \pi^{2}}{s^{2}}}+\frac{c^{\prime} s^{2}}{m^{2} \pi^{2}}(\cos (m \pi)-1)\right] \cdot \frac{\cos \left(\frac{m \pi x}{s}\right) \cdot \cosh \left(\frac{m \pi z}{s}\right)}{s \cosh \left(\frac{m \pi z_{0}}{s}\right)}
\end{aligned}
$$

where $\mathrm{m}=1,2,3 \ldots \infty$. 
If Eq. 5 is solved for an adequate number of points $P_{X Z}$, equal values of hydraulic head can be contoured and flow nets constructed. The effects of variations in the basin's shape on the geometric patterns of the flow field and hydraulic head can then be evaluated by comparing flow nets constructed for basins with different values of the parameters of regional slope c', amplitude of the local topography a, and depthto-width ratio $\mathrm{z}_{\mathrm{O}} / \mathrm{s}$.

A detailed analysis of the effect of a basin's shape on the pattern of the subsurface flow field is beyond the scope of this paper. For the present purposes it is sufficient only to discuss the effect of the undulation of the water table. This effect is the generation of hierarchically nested flow systems of different orders (Fig. 3). Strictly defined (Tóth 1963), "a flow system is a set of flow lines in which any two flow lines adjacent at one point of the flow region remain adjacent through the whole region; they can be intersected anywhere by an uninterrupted surface across which flow takes place in one direction only." Similar to the Unit Basin's basic pattern, each individual system has three identifiable segments, or flow regimes, also in the complex basin, namely: recharge, midline, and discharge. In general, however, three different orders of flow systems may be distinguished in the complex case: local, intermediate, and regional (Fig. 3).

A system is termed local if its recharge and discharge areas are contiguous; intermediate if these areas are separated by one or more local systems but do not occupy the main divide or valley bottom; and regional if it links the basin's principal divide and thalweg hydraulically. The depth of penetration of the various flow systems is a function of the relative magnitudes of the local relief and regional slope. It may exceed a thousand meters in a homogeneous rock framework under the effect of a local relief of a few tens of meters. The changes in spacing between the equipotential lines show that the intensity of the flow decreases; thus the water's residence time increases, from the local to the regional.

Patterns of multiple flow systems are characterized by alternating regions of recharge and discharge (Fig. 3). A result of the alternating arrangement is that waters recharged on a given water table mound may be destined for different discharge areas or, conversely, waters discharging in a given area side-by-side, or even mixed by diffusion and or dispersion, may have infiltrated in different parts of the basin.

Another important feature of the complex flow pattern is the possible existence of "quasi-stagnant" zones (or, mathematically, "singular points") at locations where flow systems of any order may converge from, or part toward, opposite directions (Jiang et al. 2011). In these areas, the low or zero lateral hydraulic gradients, combined with the corollary poor transport ability of the waters and converging flow directions, have significant ramifications for the accumulation of matter and/or geothermal heat, as exemplified by many anomalously warm fields of petroleum. 


\section{Effects of the rock framework's heterogeneity}

In addition to the relief of the water table, macro-scale variations in the rock's permeability is another major factor affecting the groundwater flow pattern. Because of the great diversity of its possible types an attempt is made here only to identify those permeability variations which change the general character of a flow field. The rock configurations selected by this criterion are: 1. Stratification; 2. Lenses and/ or partial layers; and 3. Faults. The effects of these heterogeneities can be best illustrated by comparing the modified patterns in a given flow domain to flow fields in homogeneous domains of similar boundary conditions, called "reference basins". A few illustrative cases are presented in this paper (additional examples can be found in Tóth 2009, pp. 50-71).

\section{Effects of stratification}

Figure 3 can be considered as a reference for a composite basin of homogeneous rock framework (Tóth 1963). The flow field of such a basin is strongly modified by a basal aquifer of high permeability (Fig. 4). The most noticeable changes are the highly intensified lateral flow along the bottom and between the two extremities of the basin and, as a necessary consequence, the increased verticality of the downward and upward flow components. As a further consequence, the intermediate flow systems have vanished completely while the local systems are strongly reduced both in areal extent and strength.

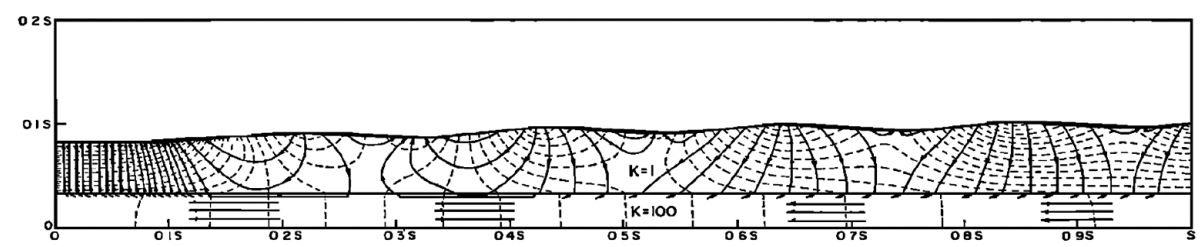

Fig. 4

Effect of highly permeable stratum beneath composite groundwater flow field (after Freeze \& Witherspoon 1967)

\section{Effects of lenses and/or partial layers}

Highly permeable lenticular rock bodies can cause significant perturbations in the fields of flow and fluid-potential, as shown by theoretical and real life studies (Tóth 1962; Freeze and Witherspoon 1967; Obdam and Veiling 1987; Tóth and Rakhit 1988; Fitts 1991). Such perturbations can encompass portions of the basin which are considerably larger than the causative rock pod and may alter basinal aspects of groundwater as, for instance, its hydrology, chemistry, temperature, and surface manifestations. Modifications of the flow field of such areal extent are termed here the basin-scale effects of lenticular rock bodies. Another type, the lens-scale effect, 
is limited to distances around the rock lens comparable to the lens' own dimensions. In applying hydrogeology to petroleum exploration, for instance, basin-scale effects should be considered when planning and/or interpreting surface geochemical measurements. Lens-scale effects, on the other hand, may serve as direct potentiometric indicators of the presence of reservoir quality rock (Tóth 2009). For the present purposes only a basin-scale situation is exemplified.

One of the most significant basin-scale effects of a lenticular rock body is the possible change in, or even reversal of, the type of groundwater flow regime between the lens and the land surface.

By means of numerical experiments Freeze and Witherspoon (1967) showed that areas of recharge and lateral flow in a homogeneous basin can be converted into areas of discharge by a highly permeable lens, or partial layer, located beneath the upslope regions of a topographic basin (Fig. 5). The effect is opposite if the lens is located in the downslope part of the basin: areas of lateral and ascending flow may be changed into regions of descending flow. In either case, the effects may be intensive enough to cause the compartmentalization of a Unit Basin into a region of several recharge, midline, and discharge areas. The appearance of multiple areas of the same hydraulic regime in a topographically featureless basin may be puzzling without an understanding of the possible effects of heterogeneities on the flow field. Such a scenario may include a seemingly inexplicable positive geothermal anomaly on the flank of a Unit Basin.

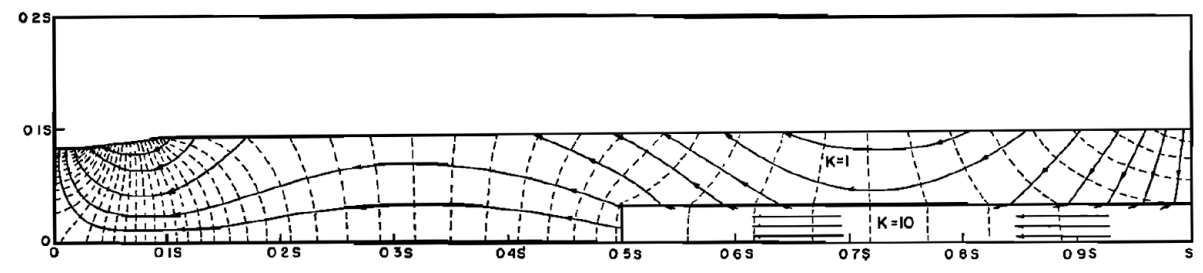

Fig. 5

Effect of highly permeable rock lens on groundwater flow field beneath recharge area of basin with linearly sloping water table and broad central valley (after Freeze \& Witherspoon 1967)

\section{Effects of faults}

A fault is a fracture, or zone of fractures, bounded by two generally planar walls of rock blocks that have been displaced in opposite directions relative to one another. Movement of the fault's walls may stop and resume several times during the geologic history of a region. In many instances, faults represent discontinuities in permeability and may thus affect the direction and intensity of the flow of formation waters. The effects of faults on formation fluid flow can vary greatly, from being insignificant to determinant. They depend on numerous factors, the most important of which include: permeability and thickness of the fault's body, the gouge; permeability of the strata juxtaposed across the fault; fluid potential values at the fault's terminations 
and, in particular, whether or not the fault outcrops at the land surface; the hydraulic regime (recharge, midline, discharge) of the fault's outcrop area, if any; the dip-angle of the fault; and the angle of incidence between flow lines and the fault's surface.

From a hydraulics viewpoint, two basic types of faults are briefly and qualitatively discussed here, namely barrier faults and conduit faults [Jones et al. (1998) contains several relevant papers, and Underschultz et al. (2005) presents some general concepts and field examples from Western Canada and the North West Shelf of Australia].

Barrier faults. A fault is considered a hydraulic barrier when its body (i.e. the rock between its bounding walls: fault breccia, fault gouge), has a contrastingly lower permeability than the formations juxtaposed across it. As an end-member of such situations a barrier fault functions and may be modeled as an impermeable boundary. Impermeability of a fault is, however, only a theoretical limiting case. It seldom, if ever, exists in nature. Assumption of absolute impermeability of faults may lead to erroneous conceptualizations of basinal flow patterns and their evolutionary history, and thus to false conclusions regarding the flow's expected consequences. The barrier effect of faults on basinal flow can be reduced by temporal changes in a fault's permeability. Such changes may be brought about by mechanical and/or chemical alterations of the fault's body or its surface, by dissolution and removal of gouge material by formation fluids, or by changes in relative positions of the aquifers and aquitards on both sides of the fault plane.

Two basic effects on groundwater flow of single, idealized barrier faults in a Unit Basin can be identified and are illustrated in Fig. 6a, b, c, d, namely i) compartmentalization, and ii) increase in hydraulic sheltering.

(i) Compartmentalization. Barrier faults divide the flow domain into cells in which the flow is controlled by the cells' own boundary conditions. Vertical and high-angle, or outcropping, barrier faults result in the development of new basins of reduced horizontal dimensions and positioned side-by-side (Fig. 6a, c, d). Hydraulic heads drop step-wise across the barriers in the direction of the flow, as is indicated by a crowding of the equipotential lines in a band along the fault on the potentiometric map. New areas of discharge develop, possibly marked by flowing artesian conditions, adjacent to the upstream sides of new areas of recharge downslope from the fault. Horizontal and low-angle faults, i.e. non-outcropping barrier faults, compartmentalize the flow domain in a vertical sense: the depth of the upper zone of strong flow is reduced, and the water becomes stagnant in the isolated basal zone (Fig. 6b).

(ii) Increase in hydraulic sheltering. Each new flow cell generated by barrier faults is accompanied by additional quasi-stagnant zones. Consequently, the relative volumes of water that are "sheltered" from active circulation, as compared with undivided basins, are thereby increased. The sheltering effect is particularly strong beneath the footwall of a barrier fault. The effect seems to increase with a decrease in the fault's dip and it reaches maximum beneath a horizontal fault (Fig. 6b).

Conduit faults. A fault is considered conduit if it enhances fluid flow through it. Two major types of conduit faults may be distinguished based on the relative 


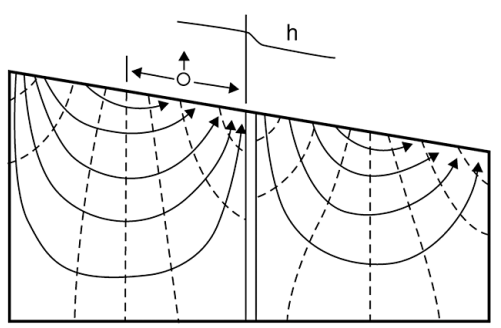

(a)

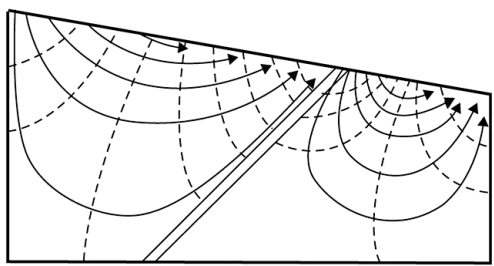

(c)

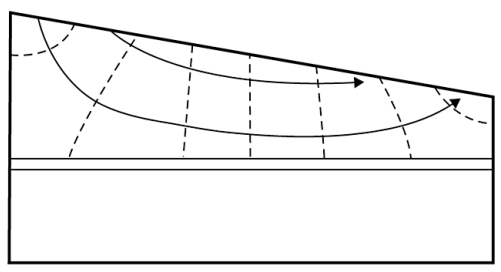

(b)

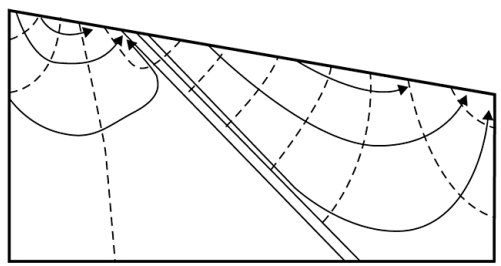

(d)

Fig. 6

Effects of barrier faults on groundwater flow patterns in the Unit Basin: a) vertical fault; b) horizontal fault; c) fault dipping opposite to direction of regional flow; d) fault dipping in direction of regional flow (Tóth 2009)

direction of flow path, namely: conductive conduit fault and barrier conduit fault. A fault is a conductive conduit if its body has a contrastingly higher permeability than the formations around it and the bulk of flow is parallel to and between its walls. It is, however, a barrier conduit if, notwithstanding the low permeability of its body, the relative displacement of its walls has resulted in hydraulic communication of permeable formations juxtaposed on its opposite sides and the bulk of flow is thus normal to its walls. Flow patterns in and around the barrier conductive faults are so diverse and complex as to defy any attempt at generalization within the scope of the present work.

The basic effect of a conductive conduit fault can, however, be briefly summarized: it is the collection and concentration of flow into the fault. It is similar to the effect of an aquifer embedded in a relatively low-permeability matrix zone (Fig. 7a, $\mathrm{b}, \mathrm{c}, \mathrm{d})$. The degree of the effect depends on the permeability contrast between the fault material and the surrounding rock, on the thickness of the fault, and on the angle of incidence, $\alpha$, between the flow lines and the fault plane.

The effect of a conductive conduit fault on the flow field is virtually nil if the angle of incidence is $\alpha \approx 90^{\circ}$ : the flow lines cross the fault un-refracted (Fig. 7a). If the angle is different from $90^{\circ}$, part of the water is deflected into and along the fault: the flux in the fault increases (Fig. 7b, c, d). If the fault outcrops then, depending on the dip direction relative to the flow, part of the water may be "shunted" to the surface 


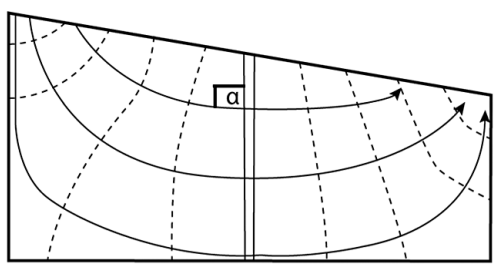

(a)

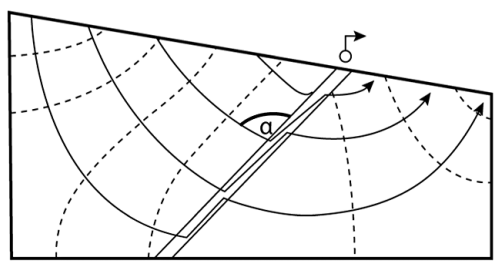

(c)

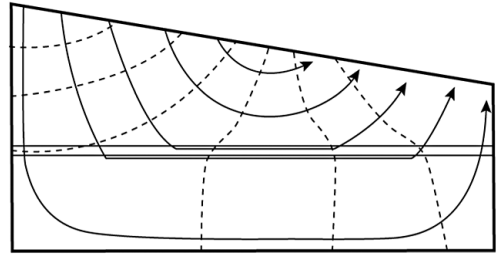

(b)

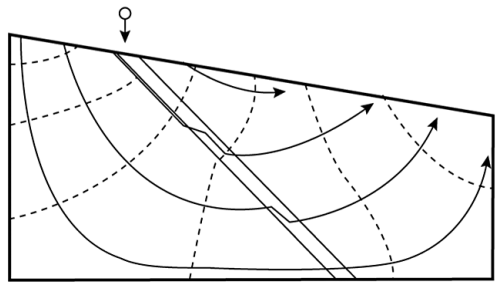

(d)

Fig. 7

Effects of conduit faults on groundwater flow patterns in the Unit Basin: a) vertical fault; b) horizontal fault; c) fault dipping opposite to direction of regional flow; d) fault dipping in direction of regional flow (Tóth 2009)

where it may appear as fault springs, whilst flow intensity is reduced on the fault's footwall side (Fig. 7c). Alternatively (Fig. 7d), additional recharge may be induced through the outcrops resulting in increased flow intensity through the basin on the downstream side of the fault. A slight reduction in flow intensity, accompanied by an expansion of the quasi-stagnant zone, occurs beneath the footwalls of the conductive faults as well. The extent of the reduction is less, however, than it is in the case of the barrier faults: the reduction is caused now by water being shunted away from hydraulically continuous parts of the basin, rather than those parts being hydraulically isolated. The difference becomes important in terms of consequences should boundary conditions change during the basin's evolutionary history.

\section{The geologic agency of gravity-driven basin-scale flow of groundwater}

The intent of this section is to advance the concept that basin-scale flow of groundwater is a general geologic agent. Both theoretical considerations and empirical observations show convincingly that regionally-moving groundwater is the basic and common cause of a wide variety of natural processes and phenomena (Tóth 2009).

That groundwater plays an active role in certain geologic and environmental processes has been recognized in numerous specific earth-science sub-disciplines 
for a long time. However, the generality of this role was not appreciated until the 1960s-1970s, when the underlying cause itself was sufficiently understood to allow, and indeed to stimulate, dedicated studies of its broader ramifications. That common cause was, as revealed at the time, the gravity-driven basinal flow of groundwater. Even during this period, however, the generalization of groundwater's role in nature was hindered by at least two factors. First, the diversity of natural phenomena related to groundwater flow effectively belies the possibility of a single common cause. Second, a lack of knowledge, or even awareness, of basinal groundwater hydraulics among specialists of various other disciplines prevents them from recognizing the cause-and-effect relation between regional groundwater flow and the particular phenomena of their interest. By way of illustrating the difficulty of envisaging a common origin, suffice it only to mention such diverse, flow-generated or modified natural phenomena as soil salinization, continental salt deposits, spatial patterns of groundwater's chemical composition, soil liquefaction, gullying, landslides, dryland ice fields, geysers, positive and negative geothermal anomalies, lake eutrophication, base-flow characteristics of streams, bog- vs. fen-type wetlands, type and quality of plant species and associations, taliks in permafrost, roll-front and tabular uranium deposits, dolomitization of limestone, karst morphology, diagenesis of certain clay minerals, some sulfide-ore deposits, and certain types of hydrocarbon accumulations.

\section{The basic causes}

Two fundamental causes make gravity-driven groundwater flow a geologic agent, namely in situ interaction between the water and its ambient environment and transport by flow that is organized into hierarchical systems of different order. The interaction of water with its surroundings results in various natural processes and products constrained by the local conditions. Patterned flow systems, on the other hand, function as sustained mechanisms of distribution of those products along regular spatial paths within the basinal flow domain. In basins where groundwater flow is controlled by the relief of the water table, the spatial distribution pattern of groundwater's effects are functionally related to identifiable and characteristic segments of the flow systems. Such a functional relation makes correlation between cause (groundwater flow) and effect (natural conditions and phenomena) feasible and verifiable.

\section{In situ interaction}

The basic cause of in situ interaction is the natural tendency toward chemical, mechanical, kinetic, or thermal equilibration between groundwater and its environment through various natural processes. As a result of such natural processes water moving through the subsurface can 1) mobilize and deposit matter and heat; 2) transport matter and heat; 3) lubricate discontinuity surfaces in the rock; and 4) generate and modify pore pressures. 
Some specific examples follow. In areas of high chemical and thermal energy, minerals are added to the water by dissolution, oxidation, attack by acids, and other processes. Relatively high mechanical energy causes the water to move away from a site, possibly carrying with it dissolved mineral matter and heat, and thus rendering the locality a supply source of minerals, water, and heat. Conversely, in regions of low chemical, thermal and kinetic energy, the water tends to converge and possibly exit the subsurface domain by discharging onto the land surface, stream bed, or lake bottom, precipitating mineral matter and losing heat. Collectively, the diverse manifestations resulting from the interaction of groundwater with its environment at a given locality may be called the in situ environmental effects of groundwater.

\section{Flow: a mechanism of systematic transport and distribution}

In situ environmental processes alone would not normally be sufficient to render groundwater a significant geologic agent, because most of them are self-limiting in time and/or randomly scattered in space. For most geologic phenomena, such as mineral deposits, geothermal anomalies, wetlands and so on to develop, it is necessary that the products of disequilibria accumulate over sufficiently long periods of time. Such accumulations usually occur by concentration within relatively small rock volumes or in areas supplied from more extensive source regions.

The only mechanism capable of producing and maintaining the required disequilibrium conditions for such a wide range of natural phenomena is the regional flow of groundwater. Individual flow systems may be thought of as conveyor belts, with their source regions being the areas of mobilization and loading, and their terminal regions the areas of delivery and deposition. The middle segments function chiefly as relatively stable environments of mass and energy transfer.

\section{Ubiquity and simultaneity}

The key reason for the great diversity of the geologic effects of groundwater is that the flow systems are active ubiquitously and simultaneously over broad spectra of space and time. Water permeates the entire porous section of the Earth's upper crust through regionally cross-formational communication, and it may penetrate to depths of $15-20 \mathrm{~km}$. Throughout this depth range water moves everywhere although at vastly different rates at different locations, possibly ranging from more than $10^{-3}$ $\mathrm{m} / \mathrm{s}$ near the land surface to less than $10^{-12}-10^{-14} \mathrm{~m} / \mathrm{s}$ at depth.

Also, the stability of individual flow systems is a function of depth and/or lateral position within the flow domain. Flow paths near the land surface and/or in unconfined domains adjust to changes in boundary conditions more readily than at great depths or in confined beds. Geologic effects of flow that require long-term hydraulic stability to be produced (e.g. mineral or petroleum accumulations) are therefore less likely to fully develop at shallow depths. 
Groundwater interacts with its environment at all depths and at all times. However, the physical, chemical and thermal conditions, the reactive matter, the processes and flow rates prevailing at different locations of the land surface and at different depths are vastly different. As a result, the rates and products of interaction between water and its environment can also be fundamentally different though generated simultaneously and at different places, but by the same agent: moving groundwater.

\section{Manifestations}

The geologic agency of moving groundwater is plausibly revealed by the numerous and diverse effects and manifestations resulting from the various flow-driven chemical, physical, and kinetic processes. Nonetheless, in spite of their collectively great number and diversity, groundwater-induced natural phenomena comprise a relatively small number of basic types, with variations within each type being due to the site-specific characteristics of the hydrogeologic environment (Tóth 1970).

In order to facilitate an easier overview of the multitude of natural effects and manifestations generated by gravity-driven groundwater flow and modified by environmental conditions, they have been grouped into six basic types with some sub-categories identified as follows (Tóth 1984): 1. Hydrological and hydraulic: i) Local water balance; ii) Regionally contrasting moisture conditions; iii) Water-level fluctuations. 2. Chemical and mineralogical: i) Areal patterns of water salinity and isotope distribution; ii) Soil salinization and continental salt deposits; iii) Weathering, dissolution and cementation; iv) Diagenesis of minerals. 3. Botanical: i) Species of plants; ii) Quality of plants. 4. Soil- and rock-mechanical: i) Liquefaction; ii) Soil erosion; iii) Slope stability. 5. Geomorphological: i) Erodability and stream valleys; ii) Karst development; iii) Geysers and mud volcanoes; iv) Frost mounds, pingos, ice fields. 6. Transport and accumulation: i) Temperature distribution patterns; ii) Low temperature sulfide ores; iii) Uranium deposits; iv) Hydrocarbon fields, methane halos, oil seeps; v) Effluents and contaminants.

The common and in most cases principal factor producing all phenomena in these categories is the effect of groundwater itself. Several levels of further divisions can be made in each case until site-specific effects and manifestations of groundwater flow are identified as shaped by the micro-environments of particular localities. Groundwater's effect as a geologic agent is manifested by a broad range of diverse, natural phenomena, some spectacular and some economically important, that include geothermal temperature patterns, sedimentary sulfide ores, roll-front and tabular uranium deposits, hydrocarbon accumulations, halos, and seeps, and eutrophication of surface-water bodies (Tóth 1999, 2009). 


\section{Geothermal phenomena in the context of gravity-driven basin-scale flow of groundwater}

\section{Heat transport}

Among the numerous processes due to or associated with regional groundwater flow systems, the transport of heat is the most visible and best understood [Schoeller 1962; Smith and Chapman 1983; Bethke 1985; Romijn et al. 1985; Rybach 1985; Beck et al. 1989; Van der Kamp and Bachu 1989; Deming et al. 1992; Deming 2002; Anderson 2005 (with 194 references!)].

Water can contain, and thus transport, heat because of its specific heat capacity, $\rho_{\mathrm{W}} \mathrm{C}_{\mathrm{W}}$, where $\rho_{\mathrm{W}}$ is the water's density and $\mathrm{C}_{\mathrm{W}}$ is its specific heat. If a temperature difference, i.e. thermal disequilibrium exists between the water and its ambient environment, heat is induced to flow in the direction of the lower temperature. The rate of heat transfer depends on numerous factors, including the thermodynamic properties of the saturated rock framework and the water, the temperature difference between the water and its environment, and the rate of the water flow. The higher the rate of heat exchange the faster the temperature difference (the temperature anomaly) is reduced between the water and the environment.

The rate of heat exchange between moving groundwater and the rock framework is essentially the result of a competition between the dissipation of heat by conduction, on the one hand, and the advective removal of heat by the flow of the water, on the other. This competition is expressed quantitatively by the Péclet Number: $P e=\frac{n \rho_{w} c_{w} q D}{\left(\rho_{m} c_{m}\right) \kappa_{m}}$, where $\mathrm{n}$ is porosity of the rock; $\rho_{\mathrm{w}}, \rho_{\mathrm{m}}$ are density of water and saturated medium, respectively; $\mathrm{q}$ is specific volume discharge; D is flow-path length; $\kappa_{\mathrm{m}}=\lambda_{\mathrm{m}} / \rho_{\mathrm{m}} \mathrm{C}_{\mathrm{m}}$ is thermal diffusivity, in which $\lambda_{\mathrm{m}}$ is thermal conductivity and $\rho_{\mathrm{m}} \mathrm{C}_{\mathrm{m}}$ is specific-heat capacity of the saturated porous medium. In cases where $\mathrm{Pe}<1$, for instance due to slow flow, dissipation of heat by conduction dominates and temperature differences between water and rock equilibrate. If, however, Pe $>1$, then advection, i.e. transport of heat by moving groundwater, prevails over the tendency for equilibration and temperature anomalies are created and/or maintained. The process is enhanced by highly permeable discontinuities such as faults, fracture zones, cavities, and solution channels, which are often major attributes in the formation of hot springs, hydrothermal ore deposits, or other types of geothermal anomalies.

Moving groundwater can thus create systematic patterns of heat distribution in drainage basins owing to its ability to exchange heat with its ambient environment. As a result, descending cold waters reduce the temperatures and temperature gradients in recharge areas below the values which would be due solely to conductive dissipation of geothermal heat. Conversely, ascending warm waters cause positive anomalies of geothermal heat and gradients in the discharge areas. The first analytical study to demonstrate this effect was due to Domenico and Palciauskas (1973; Fig. 8). 

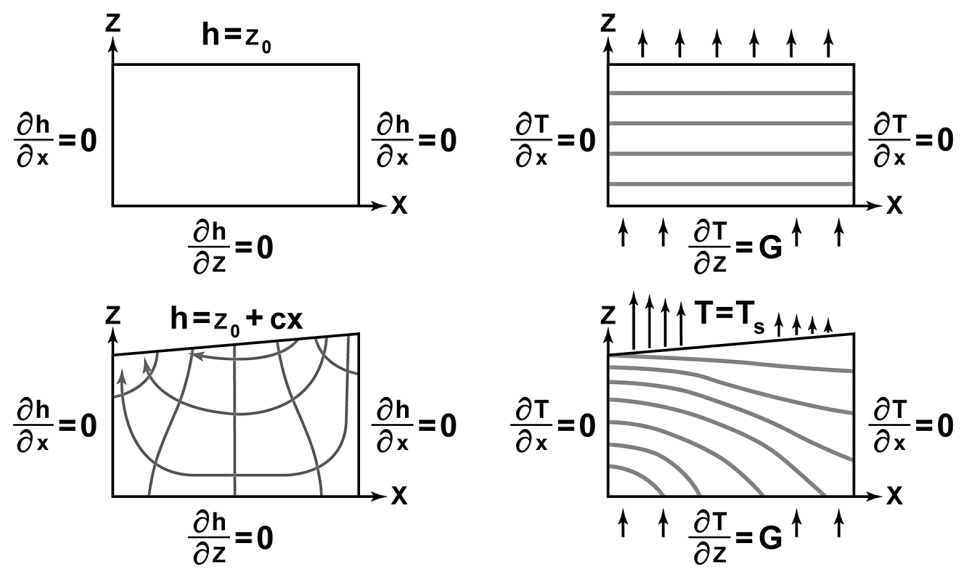

Fig. 8

The first analytical model of coupled water flow - geothermal heat flow in a topographic basin, the "Unit Basin" (Domenico \& Palciauskas 1973)
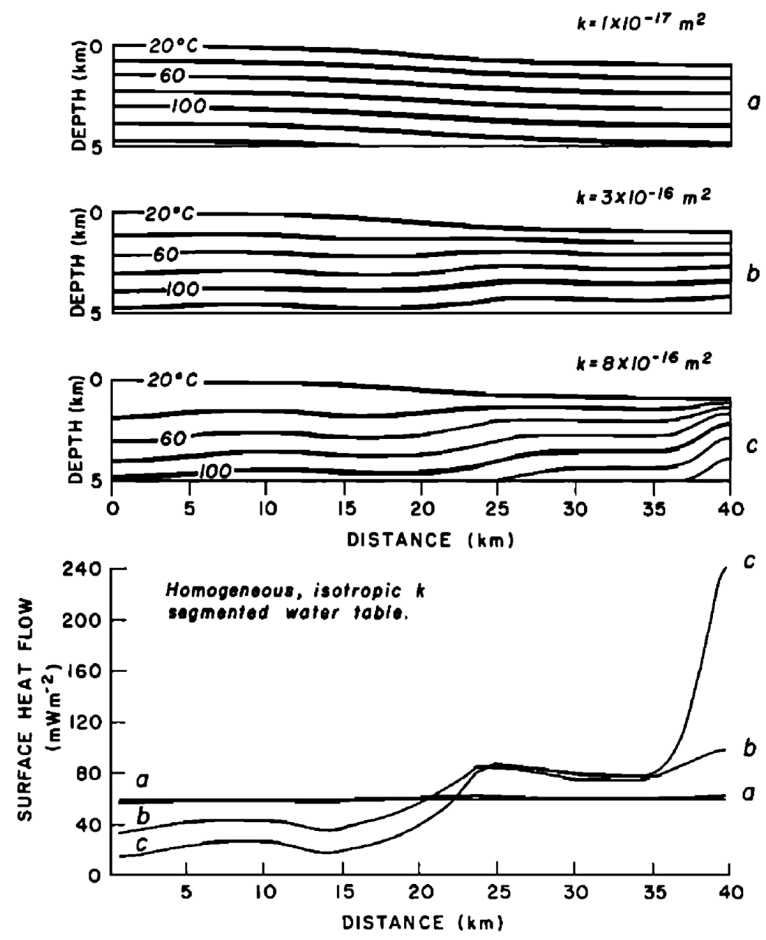

Fig. 9

Numerically simulated subsurface temperatures and heat flow in a topography-controlled basinal domain with three different permeabilities of the rock framework (Smith and Chapman 1983) 
Flow-induced geothermal anomalies can be accentuated regionally by increased flow rates resulting from increased vertical permeabilities (Fig. 9; Smith and Chapman 1983) and locally through highly permeable fault zones and bedding planes, often leading to the development of naturally occurring thermal springs.

\section{Field examples}

An example for the latter case is the temperature difference between two proximal groups of thermal springs in the Buda Hills, Budapest, Hungary (Fig. 10a). The difference in temperature was explained by the greater amount of heat which can accumulate along the longer and deeper flow path of a regional flow system than along the shallower and shorter intermediate system discharging in the same general area in the valley of the Danube river (Fig. 10b; Eröss et al. 2008).

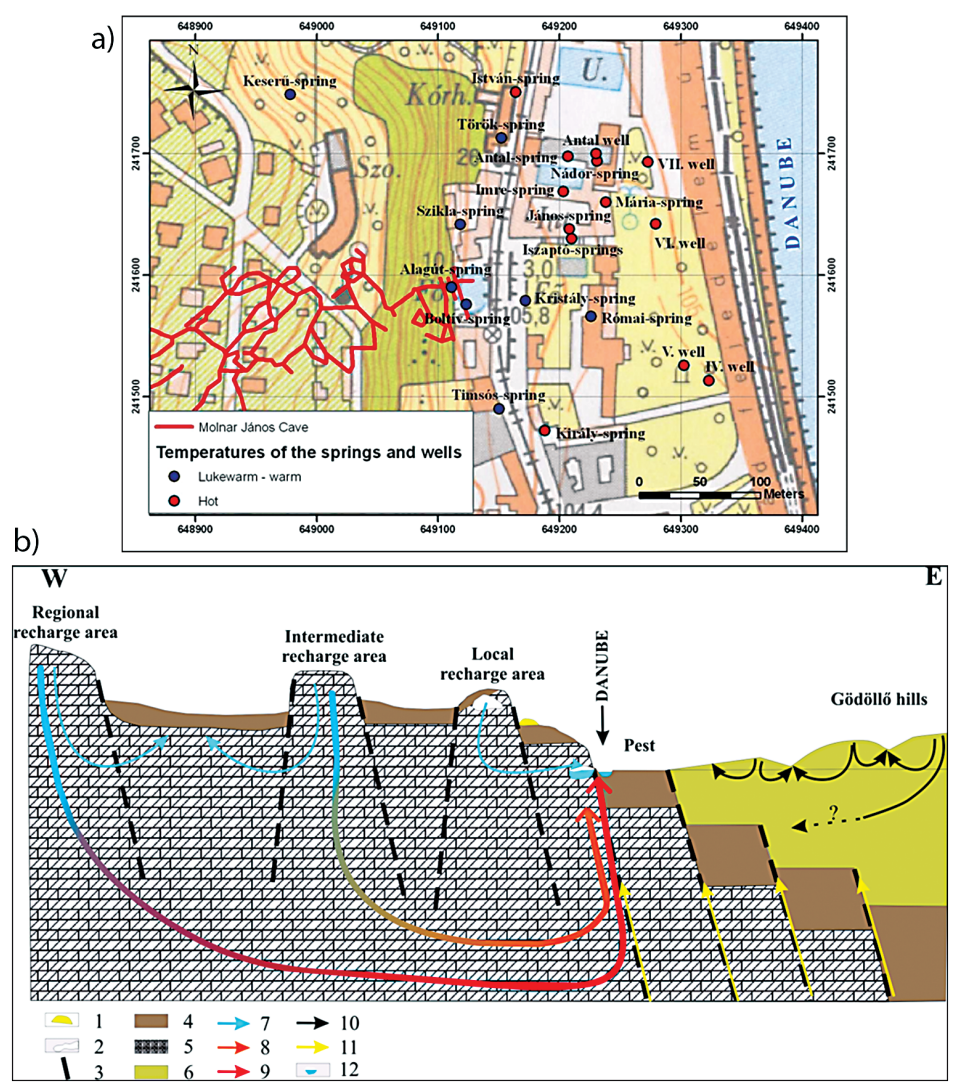

Fig. 10

Origin and effect of thermal-karst spring waters in the Buda hills, Hungary (modified from Eröss et al. 2008) 
Another example of faults localizing geothermal anomalies can be found in the Pechelbronn-Soultz area, Rhine Graben, NE France (Fig. 11; Tóth and Otto 1993. Note: The Schlumberger brothers developed the method of electrical borehole logging in these mines). Figure 11a and c show the regional topography and geologic structure of the area. Figure $11 \mathrm{~b}$ is a map of the oil fields exploited by subsurface mines between the $1850 \mathrm{~s}$ through the $1950 \mathrm{~s}$, and fault lines and isotherms at $400 \mathrm{~m}$ depth. Both the oil accumulations and thermal anomalies appear to line up along the strike of the faults. Finally, the characteristic increase in the near-surface geothermal gradient from recharge to discharge area and the free-flowing thermal well Hélions terminating in a fault are diagnostic indicators regional groundwater flow (Fig. 11d).

The effect of gravity-driven groundwater flow on geothermal heat distribution was plausibly demonstrated by Lazear (2006). The study is based on 3-D numerical simulations of groundwater flow and heat transport, constrained by field observa-

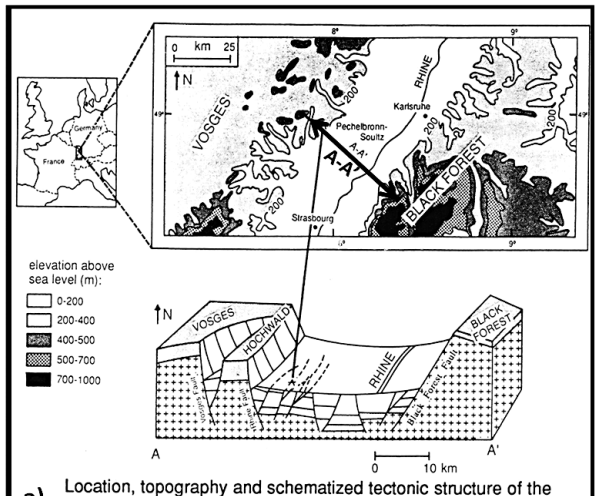

a) Uocation, topography and schematized tectonic structu

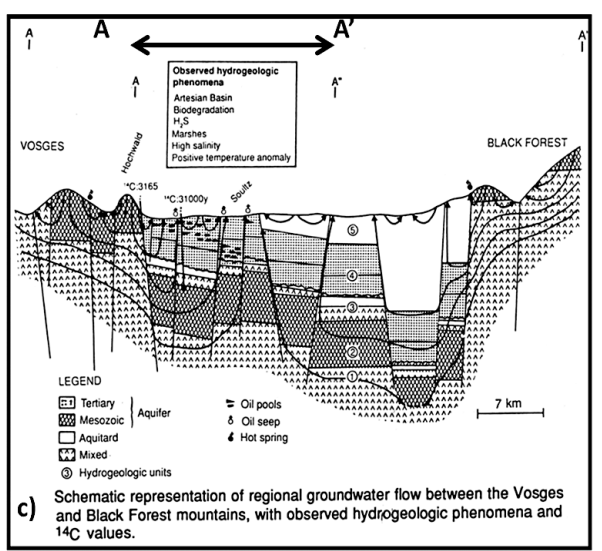

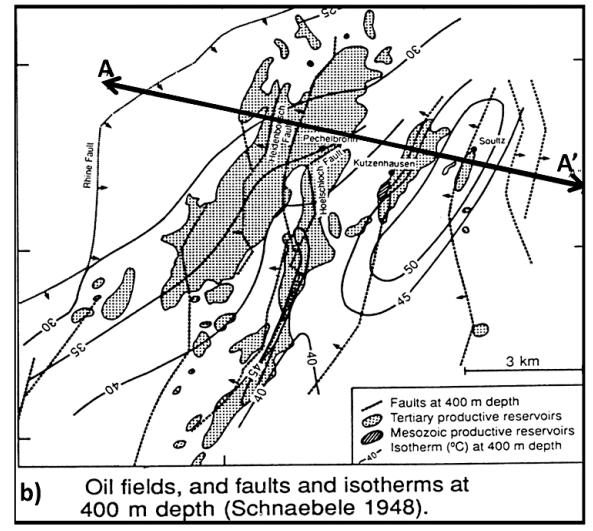

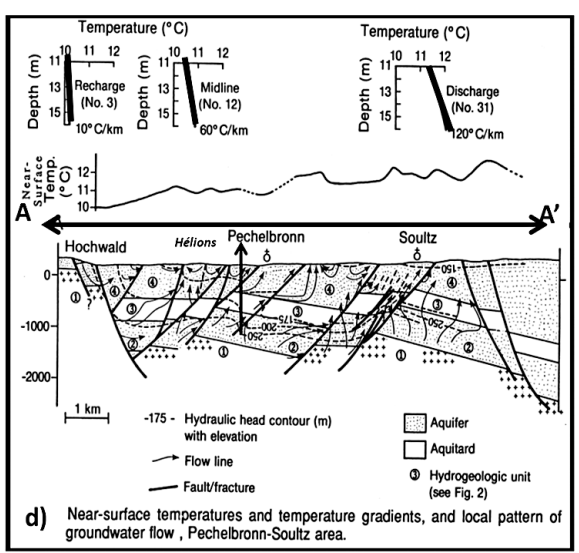

Fig. 11

Relations between gravity-drive groundwater flow, geothermal temperatures and oil deposits, Pechelbronn-Soultz area, NE France (Tóth and Otto 1993) 
tions. Its objective was "...to model the steady-state dynamic equilibrium of the hydrogeological and thermal systems." (op. cit.). The study area was a single watershed of approximately $600 \mathrm{~km}^{2}$ in areal extent and of nearly $1500 \mathrm{~m}$ relief, located on the south flank of the Grand Mesa on the western slopes of the Rocky Mountains near Cedaredge, west-central Colorado, USA.

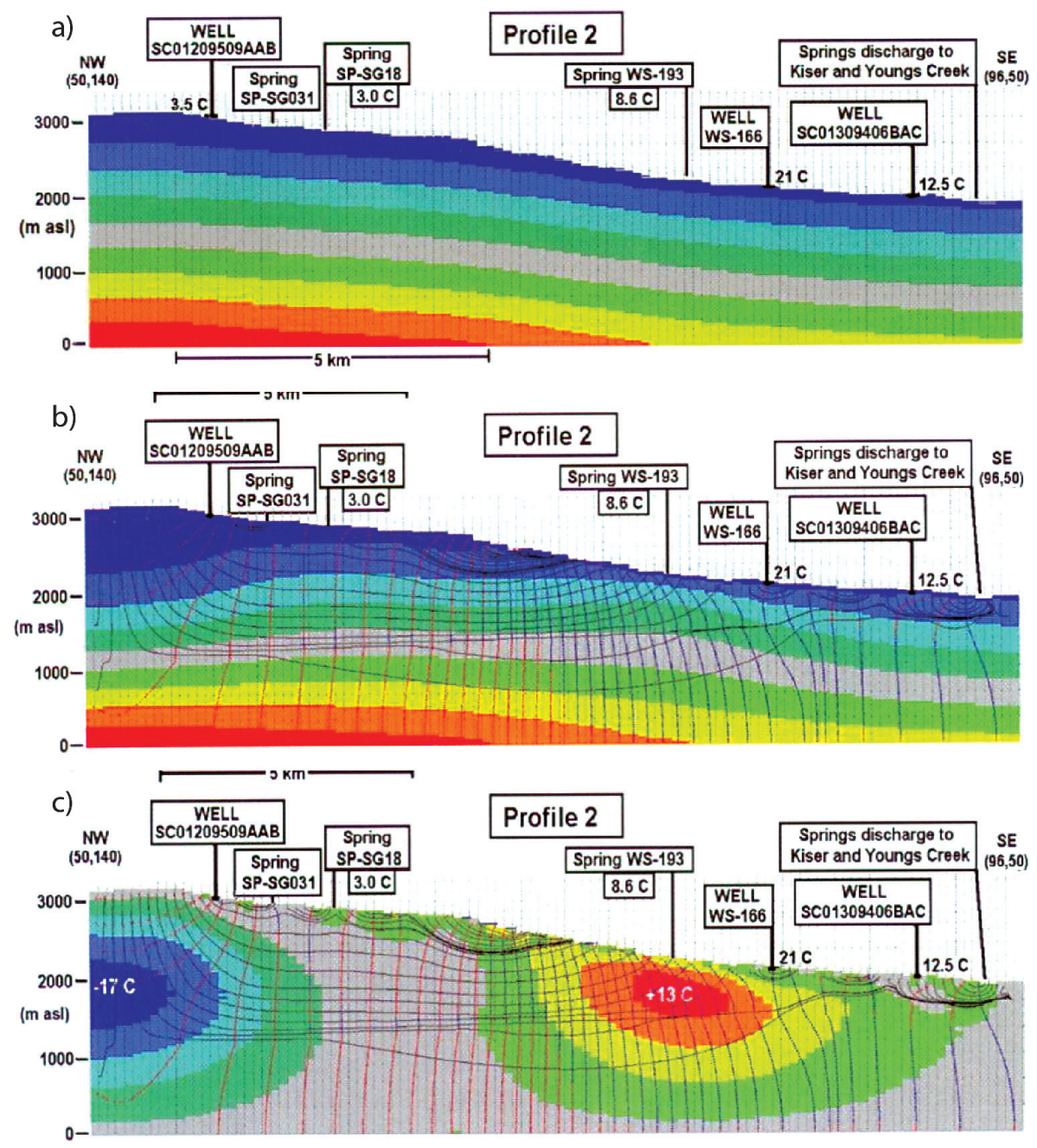

Fig. 12

Modeled conditions of subsurface water flow and heat transport along a northwest-southeast oriented vertical cross-section, Tongue Creek watershed, Delta County, Colorado, USA: a) temperature distribution due solely to conductive heat transport; b) groundwater flow and temperature distribution due to conductive and convective heat transport; c) anomalies due to heat convection by groundwater in the conductively generated temperature field (modified from Lazear, 2006) 
Results of the flow modeling were displayed in a plan view map of the flow paths and vertical cross-sections of the flow and temperature distributions. The plan view map (Lazear 2006) shows: i) Three typical ranges of flow-path lengths: $0.5-5 \mathrm{~km}$, $5-10 \mathrm{~km},>10 \mathrm{~km}$, and springs at flow-system terminations. In general, the short (and shallow) paths are associated with local topographic gradients while long flow paths penetrate to depths of several kilometers and are influenced by large-scale topographic features; ii) Shallow flow paths cross laterally over deep flow; iii) Flow paths converge toward known springs; iv) Flow paths of different lengths converge to common discharge areas where their waters may mix; v) Flow converges from a wide region into a small discharge area suggesting that proximate springs may have different water-source areas.

From the four vertical hydraulic cross-sections (Lazear 2006) the groundwater flow pattern of "Profile 2" is reproduced here in Fig. 12b, c. The flow patterns of all four of Lazear's sections, exemplified by "Profile 2", confirm the features observed in the plan view, including: divergence of flow in recharge areas under topographic highs and convergence into discharge points beneath topographic lows; flow from diverse source areas may be focused and channeled into common discharge regions; mapped springs occur where flow paths converge toward the land surface.

Heat transport and temperature distribution through the basin were simulated for two different solutions: one for conduction alone, and one for conduction plus convection by groundwater flow (Fig. 12a and b, respectively Lazear Figs 14 and 16 "Profile 2"). The conductive solution (Fig. 12a) illustrates the distribution of temperature expected from the interaction of regional heat flow with the local topography in the absence of regional groundwater flow. The calculated temperatures were compared with observed temperatures in water wells, which resulted in a root mean squared error of $5.0^{\circ} \mathrm{C}$.

The solution including convection is shown in Fig. 12b. The effect of groundwater flow is well illustrated by the downward shift of isotherms under recharge areas and their rise in regions of ascending flow. In this case the comparison with observed values resulted in a root mean squared error of $3.04{ }^{\circ} \mathrm{C}$ which is a nearly $2{ }^{\circ} \mathrm{C} \mathrm{im}$ provement over the hydrostatic, i.e. pure conductive case. Figure $12 \mathrm{c}$ shows explicitly the amount, extent, and position of the temperature changes, i.e. anomalies, caused by the regional groundwater flow.

Significant heat-flow anomalies were observed by Zielinski et al. (1985) in the subcrop areas of the major Tunp and Absaroka Thrust Faults trapping oil in the Whitney Canyon and Ryckman Creek fields, both in Wyoming, USA (Fig. 13). To quote their abstract: "A thermal study was made across a $25 \mathrm{~km}$ (15.5 mi) traverse of the Overthrust Belt in southwestern Wyoming. Estimates of relative heat flow from temperature measurements made in shallow $(<30 \mathrm{~m}$ or $98 \mathrm{ft}$ ) boreholes reveal a systematic variation of at least $400 \mathrm{~mW} / \mathrm{m}^{2}\left(10 \mu \mathrm{cal} / \mathrm{cm}^{2} \mathrm{sec}\right)$ magnitude across the study area. The cause of this variation is believed to be forced convection of heat by moving ground water. Two relative heat-flow highs coincide with zones where structurally related faults, possibly providing avenues for vertical water flow, project 


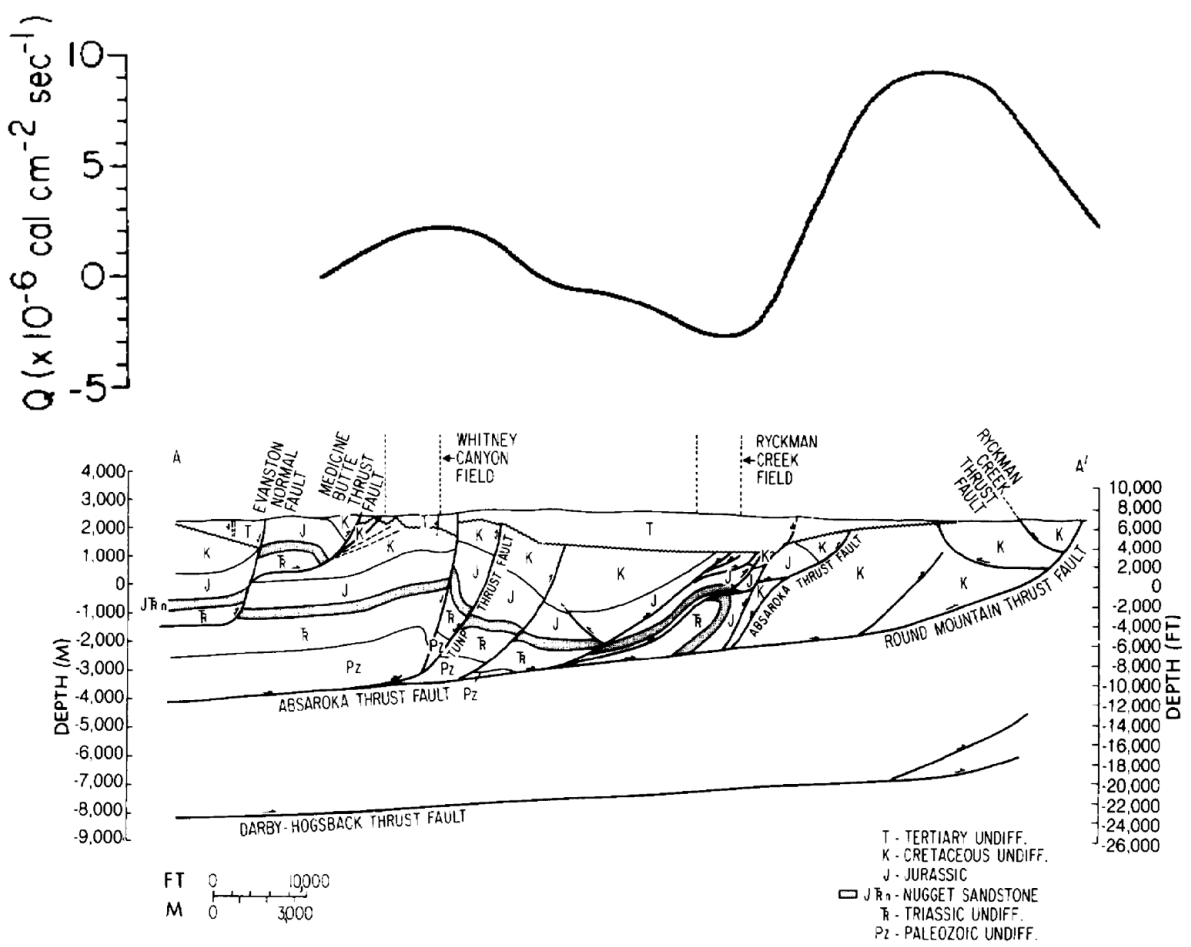

Fig. 13

Generalized heat-flow (Q) trend, Whitney Canyon and Ryckman Creek Fields, Wyoming, USA (modified from Zielinski et al. 1985)

to the surface. Between those two zones in a topographically elevated area, low and predominately negative temperature gradients were observed in opposite seasons. These shallow negative gradients are believed to exist seasonally in quasi-steadystate and could be indicative of a broad zone of ground-water recharge. The association of two relative heat-flow highs with the two major deep geologic structures implies either a direct vertical communication of deep and shallow ground water or a coupling of deeper and shallower ground-water systems. The two structures studied are hydrocarbon bearing and associated with Whitney Canyon and Ryckman Creek fields. The thermal measurements support the possibility that ascending waters have influenced the hydrocarbon migration and accumulation in these structures. Such measurements may be useful in delineating and understanding similar features in other areas."

Note that the Whitney Canyon field is more closely located to the subcrop area of its associated fault, i.e. to the heat-flow anomaly, than the Ryckman Creek field is to the subcrop of the Absaroka Thrust Fault. The reason is the difference in the dip angles of the two faults. 


\section{Summary and Conclusions}

The objective of the present essay was to explain and to support the thesis that regional heat-flow studies are incomplete without an analysis of the basin-scale flow distribution of groundwater. To this end the three fundamental elements of geothermal heat transport in an environment of basin-scale groundwater flow were reviewed which are: i) Basic patterns and properties of gravity-drive regional groundwater flow; ii) Natural manifestations of regional groundwater flow as a geologic agent; iii) Heat transport in a dynamic water-flow environment (illustrated here by examples of geothermal anomalies in modeled and real-life drainage basins).

The patterns of gravity-driven basin-scale groundwater flow were shown to be controlled by the relief of the water table and modified by permeability heterogeneities of the basin's rock framework. The basic flow pattern is generated in the "Unit Basin". The Unit Basin is bounded by three impermeable boundaries, two vertical ones on its sides and one horizontal at the base, as well as two water-table boundaries sloping linearly from the two water divides on the sides toward a central valley (Fig. 2). The single-system flow fields of either flank comprise three different hydraulic regimes, namely, the recharge, midline and discharge areas in which the flow is descending, lateral and ascending, respectively. Complex flow fields develop beneath undulating water tables which generate hierarchically-nested flow systems of different order. These systems are named, in general, as local, intermediate and regional systems (Fig. 3). In a complex field each type of flow system has the properties of a Unit Basin-style single system. Any type of flow field can be regionally modified by basin-scale heterogeneities of, e.g. lenses, partial layers and faults, as shown in Figs 4, 5, 6 and 7 .

The geologic agency of gravity-driven basinal groundwater flow is due to two basic causes: in situ interaction between water and its environment, and systematic and sustained patterns of flow. In its role as a geologic agent, two fundamentally important aspects of basinal groundwater flow are its ubiquity and simultaneity. In situ interaction is caused by disequilibria of chemical, thermal, mechanical and other types of energy between the water and the surroundings. The consequent production of matter results in a reduction of the degree of disequilibrium. However, the process, and thus the product generation, is self-limiting because it stops once equilibrium is established. Continuation of in-situ interaction, i.e. product generation, can be maintained, however, if the generated matter is advected by water flow. The matter and heat are then removed from source regions, transported in the flow systems, like in subsurface conveyor belts, toward areas of deposition where the energy conditions are such as to trap them (Fig. 3). The process can thus result in depletion, or negative anomalies, and accumulation, or positive anomalies, which are normally associated with recharge and, respectively, discharge areas.

The effectiveness of heat transport by moving groundwater may be characterized by the Péclet Number (Pe). This number is a ratio composed of the thermal and physical properties of the porous rock and water and of the rate of water flow. 
When $\mathrm{Pe}<1$, conduction of heat by the saturated rock framework prevails over advection by the moving water. If, however, $\mathrm{Pe}>1$, then heat transport by advection is stronger than by conduction. The first analytical model of geothermal heat transport by gravity-driven basin-scale groundwater flow was proposed, according to the author's knowledge, by Domenico and Palciauskas (1973) for the Unit Basin (Fig. 8). The model shows the effect of basinal water flow on geothermal heat flow by the change in shape and value of the isotherms while the hydraulic condition changes from static to dynamic. Without basinal water flow the isotherms are horizontal in a vertical steady-state heat-flow field. However, when the water flows and the heat flow is coupled to it, the isotherms are pushed down and spread out by the descending cold waters in the upslope recharge area but they are compressed and raised in the zone of warmed-up and rising waters in the basin's discharge region. Figure 9 shows the intensity of the above effect as a function of the regional permeability of the flow domain's rock framework for a theoretical situation. Calculated effects of basinal flow on geothermal temperature fields and anomalies, constrained by field data, are presented in Fig. 12 for an area of the Rocky Mountains, Colorado, USA. Three more field cases relating geothermal anomalies and regional groundwater flow conditions are shown in Figs 10, 11 and 13.

Based on the presented and other theoretical considerations and empirical evidence the regional flow fields of geothermal heat and gravity-driven groundwater must be considered as interrelated, i.e. functionally coupled. Any aspect of heat flow (position, amount, intensity, distribution pattern, temperature, variability) incorporates, therefore, some effects of the water flow. The potential effects of water flow can be inferred from the knowledge of its basinal pattern which, in turn, can be approximated from any, or any combination of, numerical modeling, field-determined fluid dynamic parameters and field manifestations of groundwater's geologic agency. On the other hand, without some knowledge of the regional groundwater flow pattern no method exists at all to assess these effects.

Knowing the groundwater flow distribution, expectations (anticipation) concerning certain geothermal features can be made, such as geothermal heat-flow and temperature patterns, including anomalies. Or the location and size of the origin of heat in observed features (heat flow anomaly, thermal springs, their source or sources) can be verified, or their lack explained. None of this is possible without an understanding of a basin's regional groundwater flow distribution. Consequently, geothermal studies of an extended area must be considered incomplete without an analysis of its basin-scale groundwater flow.

\section{Acknowledgement}

The technical assistance of Ms. Judit Déri-Takács, PhD Candidate, in preparing the manuscript is gratefully acknowledged. 


\section{References}

Anderson, M.P. 2005: Heat as a ground water tracer. - Ground Water, 43/6, pp. 951-962.

Beck, A.E., G. Garven, L. Stegena (Eds) 1989: Hydrogeological regimes and their subsurface thermal effects. - Geophysical Monograph 47/2, American Geophysical Union, Washington, DC, 158 p.

Bethke, C.M. 1985: A numerical model of compaction-driven groundwater flow and heat transfer and its application to the paleohydrology of intracratonic sedimentary basins. - Journal of Geophysical Research, 90/B7, pp. 6817-6828.

Deming, D. 2002: Introduction to Hydrogeology. - McGraw-Hill, New York, 480 p.

Deming, D., J.H. Sass, A.H. Lachenbruch, R.F. De Rito 1992: Heat flow and subsurface temperature as evidence for basin scale groundwater flow, North Slope of Alaska. - Geological Society of America Bulletin, 104, pp. 528-542.

Domenico, P.A., V.V. Palciauskas 1973: Theoretical analysis of forced convective heat transfer in regional groundwater flow. - Geological Society of America Bulletin, 84, pp. 3803-3814.

Erőss, A., J. Mádl-Szőnyi, A. Csoma 2008: Characteristics of discharge at Rose and Gellért Hills, Budapest, Hungary. - Central European Geology, 51/3, pp. 267-281.

Fitts, C.R. 1991: Modeling three-dimensional flow about ellipsoidal inhomogeneities with application to flow to a gravel-packed well and flow through lens-shaped inhomogenities. - Water Resource Research 27/5, pp. 815-824.

Freeze, R.A., P.A. Witherspoon 1967: Theoretical analysis of regional groundwater flow. 2. Effect of water table configuration and subsurface permeability variation. - Water Resources Research, 3/2, pp. 623-634.

Jiang, X.W., X.S. Wang, L. Wan, S. Ge 2011: An analytical study on stagnation points in nested flow systems in basins with depth-decaying hydraulic conductivity. - Water Resources Research, 47/1, pp. n/a.

Jones, G., Q.J. Fisher, R.J. Knipe (Eds) 1998: Faulting, fault sealing and fluid flow in hydrocarbon reservoirs. - Geological Society Special Publication, 147, London, 319 p.

Lazear, G.D. 2006: Evidence for deep groundwater flow and convective heat transport in mountainous terrain, Delta County, Colorado. U.S.A. - Hydrogeology Journal, 14/8, pp. 1582-1598.

Obdam, A.N.M, E.J.M. Veiling 1987: Elliptical inhomogeneities in groundwater flow. An analytical description. - Journal of Hydrogeology, 95, pp. 87-96.

Robinson, N.I., A.J. Love 2013: Hidden channels of groundwater flow in Tóthian drainage basins. Advances in Water Resources, 68, pp. 71-78.

Romijn, E., E. Groba, G. Lüttig, K. Fiedler, R. Laugier, E. Löhnert, C. Garagunis (Eds) 1985: Geothermics Thermal-Mineral Waters and Hydrogeology. - Theophrastus Publications S.A., Athens, 264 p.

Rybach, L. (Ed) 1985: Heat Flow and Geothermal Processes. - Proceedings of IUGG Inter-disciplinary Symposium, 10, Hamburg, Journal of Geodynamics, Special Issue 4.

Schnaebele, R. 1948: Monographie géologique du champ pétrolifière de Pechelbronn. - Mém. Serv. Carte Géol. Als. Lorr., 7, 254 p.

Schoeller, H. 1962: Les Eaux Souterraines. - Masson \& Cie, Paris, 642 p.

Smith, L., D.S. Chapman 1983: On the thermal effects of groundwater flow 1. Regional scale systems. Journal of Geophysical Research, 88, pp. 593-608.

Tóth, J. 1962: A theory of groundwater motion in small drainage basins in central Alberta, Canada. Journal of Geophysical Research, 67/11, pp. 4375-4387.

Tóth, J. 1963: A theoretical analysis of groundwater flow in small drainage basins. - Journal of Geophysical Research, 68/10, pp. 4795-4812.

Tóth, J. 1970: A conceptual model of the groundwater regime and the hydrogeologic environment. Journal of Hydrology, 10/2, pp. 164-176.

Tóth, J. 1980: Cross-formational gravity flow of groundwater: A mechanism of the transport and accumulation of petroleum (The generalized hydraulic theory of petroleum migration). - In: Roberts, W.H., R.J. Cordell (Eds) 1980: Problems of Petroleum Migration. AAPG Studies in Geology, 10, Tulsa, pp. 121-167. 
Tóth, J. 1984: The role of regional gravity flow in the chemical and thermal evolution of ground water. - In: Hitchon, B., E.I. Wallick (Eds): Proceedings, Practical Applications of Ground Water Geochemistry. First Canadian/American Conference on Hydrogeology, National Water Well Association and Alberta Research Council, Worthington, pp. 3-39.

Tóth, J. 1999: Groundwater as a geologic agent: An overview of the causes, processes, and manifestations. - Hydrogeology Journal, 7/1, pp. 1-14.

Tóth, J. 2009: Gravitational systems of groundwater flow: Theory, Evaluation, Utilization. - Cambridge University Press, Cambridge, 297 p.

Tóth, J., C.J. Otto 1993: Hydrogeology and oil-deposits at Pechelbronn-Soultz, Upper Rhine Graben. Acta Geologica Hungarica, 36/4, pp. 375-393.

Tóth, J., K. Rakhit 1988: Exploration for reservoir quality rock bodies by mapping and simulation of potentiometric surface anomalies. - Bulletin of Canadian Petroleum Geology, 36/4, pp. 362-378.

Underschultz, J.R., C.J. Otto, R. Bartlett 2005: Formation fluids in faulted aquifers: Examples from the Foothills of Western Canada and the North West Shelf of Australia. - In: Boult, P., J. Kaldi (Eds): Evaluating Fault and Caprock Seals. AAPG, Hedberg Series, 2, pp. 247-260.

Walker, G., M. Gilfedder, R. Evans, Ph. Dyson, M. Stauffacher 2003: Groundwater Flow System Framework: Essential tools for planning salinity management. - Murray-Darling Basin Commission, MDBC Publication 15/03. Canberra, Australia.

Van der Kamp, G., S. Bachu 1989: Use of dimensional analysis in the study of thermal effects of various hydrogeological regimes. - In: Beck, A.E., G. Garven, L. Stegena (Eds): Hydrogeological Regimes and their Subsurface Thermal Effects. Geophysical Monograph 47/2, American Geophysical Union, Washington, DC., pp. 23-28.

Wang, H.F., M.P. Anderson 1982: Introduction to Groundwater Modeling. Finite Difference and Finite Element Methods. - WH Freeman and Co, San Francisco, 237 p.

Zielinski, G.W., J.A. Drahovzal, G.M. Decoursey, J.M. Ruperto 1985: Hydrothermics in the Wyoming Overthrust belt. - AAPG Bulletin, 69/1, pp. 699-709.

Zijl, W., M. Nawalany 1993: Natural groundwater flow. - Lewis Publishers, Boca Raton, 321 p. 